\title{
Prevalence and factors associated with unplanned pregnancy in The Gambia: findings from 2018 population-based survey
}

\author{
Amadou Barrow ${ }^{1 *}$, Amienatta Jobe ${ }^{2}$, Sulayman Barrow ${ }^{3}$, Ebrima Touray ${ }^{4}$ and Michael Ekholuenetale ${ }^{5}$
}

\begin{abstract}
Background: Unplanned pregnancy is a public health issue that has detrimental implications for the mother and baby alike. However, few studies have been conducted in The Gambia on this subject. As a result, the prevalence of unplanned pregnancy among women of reproductive age in The Gambia was investigated, as well as the factors associated with it.

Methods: The Gambia's Multiple Indicators Cluster Survey (MICS) was used to evaluate the 2018 results. Data was obtained from 3790 women aged 15 to 49 who had also given birth. The univariate analysis was conducted using percentage. The adjusted odds ratios (AOR) were determined using a multivariable logistic regression model (with corresponding 95\% confidence interval (CI)). The degree of statistical significance was set at 5\%.
\end{abstract}

Results: Approximately $25.3 \%$ (95\% Cl: $23.1 \%-27.6 \%$ ) of the women reported unplanned pregnancy. Women aged 30-34 years had 45\% reduction in unplanned pregnancy, when compared with those aged 15-19 years ( $A O R=0.55$; 95\% Cl: 0.32-0.94). The Fula and non-Gambian women had 30\% and 45\% reduction in unplanned pregnancy respectively, when compared with Mandinka women. Those who had no functional difficulties had $47 \%$ reduction in unplanned pregnancy, when compared with women who had functional difficulties ( $\mathrm{AOR}=0.53 ; 95 \% \mathrm{Cl}: 0.30,0.91$ ). Respondents who had given births to $3-4$ and $5+$ children were 1.79 and 3.02 times as likely to have unplanned pregnancy, when compared with women who had given birth to 1-2 children. Single/unmarried women were 11.38 times as likely to have unplanned pregnancy, when compared with women currently married/in union (AOR $=11.38$; $95 \%$ Cl: 6.38, 20.29). Local Government Area of residence was significantly associated with unplanned pregnancy. Furthermore, women who were neither happy nor unhappy and $18+$ at sexual debut were 1.39 and 1.34 times as likely to have unplanned pregnancy, when compared with the very happy women and those $<18$ at sexual debut respectively.

Conclusion: The rate of unintended pregnancies was large (25.3\%). Several causes have been linked to unplanned pregnancies. These results suggest that further efforts are required to enhance women's sex education, expand access to family planning services, and provide affordable health care to high-risk women in order to minimize unintended pregnancies.

Keywords: Family planning, Pregnancy, Abortion, Unintended, Unwanted, Untimed, Gambia

\footnotetext{
*Correspondence: abarrow@utg.edu.gm

${ }^{1}$ Department of Public \& Environmental Health, School of Medicine \&

Allied Health Sciences, University of The Gambia, Kanifing, The Gambia

Full list of author information is available at the end of the article
} original author(s) and the source, provide a link to the Creative Commons licence, and indicate if changes were made. The images or other third party material in this article are included in the article's Creative Commons licence, unless indicated otherwise in a credit line to the material. If material is not included in the article's Creative Commons licence and your intended use is not permitted by statutory regulation or exceeds the permitted use, you will need to obtain permission directly from the copyright holder. To view a copy of this licence, visit http://creativecommons.org/licenses/by/4.0/. The Creative Commons Public Domain Dedication waiver (http://creativeco mmons.org/publicdomain/zero/1.0/) applies to the data made available in this article, unless otherwise stated in a credit line to the data. 


\section{Background}

Unplanned pregnancy is a major public, clinical, and social health problem around the world because it often leads to induced abortion and subsequent complications, which are often caused by insufficient abortion care services, particularly in resource-constrained settings [1]. Between 2015 and 2019, there were 121 million unintended pregnancies, leading to a global average of 64 unintended pregnancies per 1000 women aged 15 to 49 years [2]. About $61 \%$ of unintended pregnancies resulted in abortion, resulting in a global abortion rate of 39 abortions per 1,000 women aged 15 to 49 [2]. Unintended pregnancies account for around 44\% of all pregnancies globally, with around 55\% of unintended pregnancies in developed countries ending in abortion [3]. In sub-Saharan Africa (SSA), there was $33.9 \%$ unintended pregnancy rate [4]. The rate of unintended pregnancies and their effects can be minimized by increasing the availability, accessibility and affordability of contraception [5]. Individuals are increasingly trying to avoid unwanted births due to long-term global decreases in ideal family size and changes in the age at which people want to start families [6].

Unplanned pregnancy can be attributed to non-use of modern contraceptive methods among sexually active women [7]. More than 200 million women in developing countries choose to postpone their next pregnancy or stop childbirth altogether, but many still rely on inadequate or obsolete contraceptive methods, if they use contraception at all [8]. According to a previous report, 342 203 women died from maternal causes, but contraceptive use avoided 272040 maternal deaths (44\%), meaning that the number of maternal deaths would have been 1.8 times higher if contraceptive use had not been used [9]. A further 104 000 maternal deaths per year could be avoided by addressing the unmet need for contraceptives (29\% reduction) [9]. In several resource-poor countries, the number of unintended pregnancies and unmet contraception needs remains high. Evidence-based research has shown that the use of contraception to avoid unplanned pregnancy is a substantial and successful primary prevention method $[10,11]$.

If family planning needs are met to delay, space, and limit the number of children women have, millions of girls and women in the world's poorest countries, including The Gambia, will see an improvement in their living conditions. Albeit, nearly 222 million women in developing countries do not use a modern form of contraception to prevent pregnancy $[12,13]$. The third Sustainable Development Goal (SDG-3) prioritizes universal access to sexual and reproductive health care services, including reducing unmet contraceptive needs. The third Sustainable Development Goal (SDG-3) aims to ensure healthier lives and foster well-being for everyone at all ages [14]. To achieve this, adequate and long-term efforts are needed to eliminate several barriers to health-care service use, including family planning, especially in resource-constrained settings.

Evidence-based studies have reported about 18.4\% prevalence of unplanned pregnancy among grand multiparous Gambian women [15] and 15.3\% of unintended pregnancy among women aged 15-49 years in The Gambia [16]. While substantial resources have been allocated in Gambia to the provision of modern contraceptive methods, the total fertility rate is still high at 5.4 births per woman and an annual growth rate of 3.3 percent [17]. In all health centres in the region, the Gambian National Reproductive Health Policy (NRHP) provides for the provision of free family planning services. Despite this massive investment by the government and foreign donors in family planning, the contraceptive prevalence remains low $(30.4 \%)$ [18], with about $17.6 \%$ of women having unmet family planning needs [19]. According to The Gambia Bureau of Statistics, births could be wanted at the time (planned), wanted at a later time (mistimed), or not wanted at all (unwanted) [17].

Unplanned pregnancy has been associated with many factors, including socio-demographic and economic factors, early sexual debut, accessibility to health care services, unmet need for family planning, higher parity, failure of contraceptives, preference of the partner for children, and domestic abuse [20-23]. Furthermore, age and age at sexual debut, religion, marital status and parity, education, residence have been reported as determinants of unplanned pregnancy [4]. To the best of our knowledge, there is no study in the Gambia that has examined the patterns and determinants of unplanned pregnancy among Gambian women of childbearing age. The objective of this study was to examine the prevalence and factors associated with unplanned pregnancy among women of reproductive age in The Gambia.

\section{Methods \\ Data extraction}

The study relied on secondary data from the Gambia's 2018 Multiple Indicator Cluster Survey (MICS). The study's data came from 3790 women of reproductive age who had recently given birth. The Gambia MICS, which took place in 2018, provided technical guidance on the quality or excellence of survey information to be collected, statistical monitoring, data collection, and data analysis, with the goal of improving the country's national statistical capability. MICS ensures the measurement of key points on which countries depend to generate data used in policy formulations and program planning in order to track their progress toward 
achieving the SDGs, as well as Gambia's National Development Plan (NDP) and other international obligations to which the country is a signatory. The MICS' contribution to improving Gambian data and device control, as well as providing technical expertise in the design, implementation, and analysis of such systems. The creation of the MICS program by the United Nations International Children's Emergency Fund (UNICEF) was largely motivated by the need to assist countries in gathering data on a global scale.

The Gambia MICS 2018 sample was designed to provide estimates for a large number of indicators on the situation of children and women at the national level, for urban and rural areas, and for the eight LGAs: Banjul, Kanifing, Brikama, Mansakonko, Kerewan, Kuntaur, Janjanbureh, and Basse. A multistage stratified cluster randomized sampling was used in the survey. The first stage involved randomly selecting enumeration areas (EAs) or clusters within each substratum with a probability proportional to size. The main sampling strata within each local government area were identified as urban and rural areas, and the sample of households was selected in two stages. The primary sampling unit was household. Following the completion of a household listing within the selected enumeration areas, a systematic sample of 20 households was drawn in each sample enumeration area. During the fieldwork period, all enumeration areas were visited. The global MICS program's procedures and standard guidelines were adapted to The Gambia MICS 2018 final questionnaires and used throughout the survey.

\section{Variable selection and measurement Outcome}

The study outcome was unplanned pregnancy. The outcome variable was derived from the question; "Wanted last child then?" This was coded as " 1 " if a respondent answered "no" for unplanned pregnancy and "0" if otherwise. According to The Gambia Bureau of Statistics (GBS), births wanted at the time is regarded as planned pregnancy [17].

\section{Explanatory variables}

Table 1 showed the explanatory variables used in this study. The list of variables include: age (in years), household wealth quintiles, education, health insurance, ethnicity, functional disabilities, parity, marital status, age at first marriage/union, Local Government Area (LGA), residential status, overall happiness, age (in years) at sexual debut, ever used any method to avoid pregnancy, reading newspaper/magazine, listening to radio, watching television and family motility. Household wealth index quintiles was computed using a set of household assets in line with previous studies $[24,25]$. See Table 1 for the details.

\section{Ethical consideration}

We used publicly available datasets that were already accepted in March 2017 by the Government of Gambia and the Scientific Coordinating Committee (SCC)

Table 1 Description/definition of explanatory variables

\begin{tabular}{|c|c|c|}
\hline $\mathbf{S} / \mathbf{N}$ & Variable & Description/definition \\
\hline 1 & Age (in years) & $15-19,20-24,25-29,30-34,35-39,40-44,45-49$ \\
\hline 2 & Household wealth quintiles & poorest, poorer, middle, richer, richest \\
\hline 3 & Education & pre-primary or none, primary, secondary/higher \\
\hline 4 & Health insurance & With insurance versus without insurance \\
\hline 5 & Ethnicity & Mandinka, Wollof, Fula, Jola, Sarahule, other ethnic groups and non-Gambians \\
\hline 6 & Functional disabilities & has functional difficulties versus has no functional difficulties \\
\hline 7 & Parity & $1-2,3-4,5+$ \\
\hline 8 & Marital status & currently married/in union, formerly married/in union, single \\
\hline 9 & Age at first marriage/union & $<18,18-24,25+$, never married \\
\hline 10 & Local Government Area (LGA) & Banjul, Kanifing, Brikama, Mansakonko, Kerewan, Kuntaur, Janjanbureh, Basse \\
\hline 11 & Residential status & urban versus rural \\
\hline 12 & Overall happiness & very happy, somewhat happy, neither happy nor unhappy, somewhat unhappy, very unhappy \\
\hline 13 & Age (in years) at sexual debut & $<18,18+$, at first marriage \\
\hline 14 & Ever used any method to avoid pregnancy & yes versus no \\
\hline 15 & Reading newspaper/magazine & yes versus no \\
\hline 16 & Listening to radio & yes versus no \\
\hline 17 & Watching television & yes versus no \\
\hline 18 & Family motility & native (lived $5+$ years in the location) versus visitor (lived $<5$ years in the location) \\
\hline
\end{tabular}


of the Medical Research Council (MRC) for the survey protocol. It is also on record that each survey participant received verbal consent. The ability to participate in the survey and their confidentiality and anonymity were guaranteed for all the survey respondents.

\section{Statistical analysis}

Stata survey ('svy') module was used to adjust for stratification, clustering and sampling weights. The Variance Inflation Factor (VIF) was used to assess multicollinearity, using a cut-off of 10 to detect significant concerns [26]. There was no variable omitted in the model due to lack of multicollinearity. Weighted percentages were used to describe the demographic characteristics.. To estimate the adjusted odds ratios, all statistically significant variables from the bivariate analysis were included in the multivariable logistic regression model using a $20 \%$ significance level. The predictive margins was conducted as a post-estimation of logit model. The model is presented thus;

$$
\operatorname{Pr}(Y=1 \mid \operatorname{Set}[\mathrm{E}=\mathrm{e}])=\sum_{z} \widehat{p}_{e z} \operatorname{Pr}(Z=z) ;
$$

where $\operatorname{Set}[E=e]$ reflects putting all observations to a single exposure level e, and $\mathrm{Z}=\mathrm{z}$ refers to a given set of observed values for the covariate vector $Z$. Furthermore, $\widehat{p}_{e z}$ is the predicted probabilities of unplanned pregnancy (outcome variable) for any $\mathrm{E}=\mathrm{e}$ and $\mathrm{Z}=\mathrm{z}$. The margin estimates indicate a weighted average over the distribution of the covariates and are equal to estimates got by standardizing to the entire population. As a post logit test, the exposure $E$ is set to the level $e$ for all women in the dataset, and the logit coefficients are used to compute predicted probabilities for every woman at their observed covariate pattern and newly exposure value [27, 28]. At $p<0.05$, the statistical significance was determined in the adjusted model. For data processing, Version 14 of Stata (StataCorp., College Station, TX, USA) was used.

\section{Results}

Overall, approximately $25.3 \%$ (95\% CI: $23.1 \%-27.6 \%)$ of the women reported unplanned pregnancy. Table 2 showed the results of unplanned pregnancy among the Gambian women. In addition, there were differences in unplanned pregnancy across the levels of women characteristics. Unplanned pregnancy was higher among advanced age women. Women aged 40-44 and $45-49$ years had $30.1 \%$ and $40.0 \%$ unplanned pregnancies respectively. Those without health insurance, from Jola ethnic group, have functional disabilities, $5+$ number of children ever born and single/never married had 25.6\%, $37.2 \%, 42.3 \%, 29.5 \%, 77.8 \%$ unplanned pregnancy respectively. See Table 2 below for the details.
In Table 3, we showed the factors associated with unplanned pregnancy among Gambian women. Women aged 30-34 years had $45 \%$ reduction in unplanned pregnancy, when compared with those aged 15-19 years $(\mathrm{AOR}=0.55$; 95\% CI: 0.32, 0.94). The Fula and non-Gambian women had 30\% (AOR $=0.70$; 95\% CI: 0.54, 0.92) and $45 \%(\mathrm{AOR}=0.55 ; 95 \% \mathrm{CI}: 0.36,0.86)$ reduction in unplanned pregnancy respectively, when compared with the Mandinka women. Those who had no functional difficulties had $47 \%$ reduction in unplanned pregnancy, when compared with women who had functional difficulties (AOR $=0.53 ; 95 \%$ CI: 0.30, 0.91). Respondents who had given births to $3-4$ and $5+$ children were 1.79 $(\mathrm{AOR}=1.79 ; 95 \% \mathrm{CI}: 1.34,2.39)$ and $3.02(\mathrm{AOR}=3.02$; 95\% CI: $2.08,4.39)$ times as likely to have unplanned pregnancy respectively, when compared with women who had given birth to 1-2 children. Single women were 11.38 times as likely to have unplanned pregnancy, when compared with women currently married/in union $(\mathrm{AOR}=11.38$; 95\% CI: 6.38, 20.29). LGA was significantly associated with unplanned pregnancy. Furthermore, women who were neither happy nor unhappy and $18+$ at sexual debut were 1.39 and 1.34 times as likely to have unplanned pregnancy, when compared with the very happy women and those $<18$ at sexual debut. See Table 3 for the details.

In Table 4, the predictive margins estimates were calculated to decipher the effects of the factors associated with unplanned pregnancy. From the predictive margins results, assuming the distribution of all factors remained the same among women, but every woman was aged 15-19 years or without health insurance, we would expect $26.9 \%$ and $21.0 \%$ of unplanned pregnancy respectively. If every woman had functional difficulties, we would expect $31.6 \%$ of unplanned pregnancy. If instead the distribution of women's age, education, health insurance, ethnicity, functional difficulties, parity, were as observed and other covariates remained the same among women, but all women lived in Banjul, we would expect $33.3 \%$ of unplanned pregnancy. See Table 4 for the details.

\section{Discussion}

To the best of our knowledge, this is the first study that has examined the prevalence and factors associated with unplanned pregnancy in The Gambia using a population-based data. Based on the findings of this study, approximately one-quarters of Gambian women of reproductive age reported unplanned pregnancy. Since poor use of modern contraceptive methods is the origin of unintended pregnancy [18], the relatively high prevalence of unplanned pregnancy is expected. This may be a major contributing factor to the degree of unintended 
Table 2 Distribution of unplanned pregnancy across women's characteristics $(n=3,790)$

\begin{tabular}{|c|c|c|c|}
\hline Variable & $\begin{array}{l}\text { Unweighted number of } \\
\text { women }\end{array}$ & $\begin{array}{l}\text { Weighted percentage of } \\
\text { women; } 95 \% \mathrm{Cl}\end{array}$ & $\begin{array}{l}\text { Weighted percentage of } \\
\text { unplanned pregnancy; } \\
95 \% \mathrm{Cl}\end{array}$ \\
\hline \multicolumn{4}{|l|}{ Age } \\
\hline 15-19 & 294 & $5.6(5.1-6.3)$ & $23.7(16.9-32.2)$ \\
\hline $20-24$ & 941 & $17.2(16.2-18.3)$ & $28.7(24.2-33.8)$ \\
\hline $25-29$ & 990 & $20.9(19.7-22.1)$ & $22.1(18.3-26.5)$ \\
\hline $30-34$ & 821 & $20.0(18.9-21.1)$ & $21.9(18.3-26.0)$ \\
\hline $35-39$ & 523 & $17.1(16.2-18.1)$ & $28.8(23.7-34.6)$ \\
\hline $40-44$ & 178 & $11.3(10.5-12.1)$ & $30.1(22.0-39.6)$ \\
\hline $45-49$ & 43 & $7.8(7.2-8.5)$ & $40.0(22.1-61.0)$ \\
\hline \multicolumn{4}{|l|}{ Wealth index quintiles } \\
\hline Poorest & 1362 & $19.4(17.3-21.7)$ & $25.1(21.9-28.7)$ \\
\hline Second & 885 & $19.3(17.0-21.8)$ & $29.6(24.8-34.8)$ \\
\hline Middle & 683 & $19.7(17.4-22.2)$ & $25.8(21.3-31.0)$ \\
\hline Fourth & 470 & $21.0(18.4-23.9)$ & $25.1(20.2-30.7)$ \\
\hline Richest & 390 & $20.6(18.1-23.5)$ & $19.2(14.7-24.5)$ \\
\hline \multicolumn{4}{|l|}{ Education } \\
\hline Pre-primary or none & 2083 & $47.8(45.6-49.9)$ & $23.7(21.0-26.7)$ \\
\hline Primary & 706 & $17.0(15.8-18.2)$ & $24.4(19.8-29.6)$ \\
\hline Secondary + & 1001 & $35.3(33.3-37.3)$ & $27.9(24.5-31.7)$ \\
\hline \multicolumn{4}{|l|}{ Health insurance } \\
\hline With insurance & 37 & $2.4(1.9-3.0)$ & $7.3(2.3-20.9)$ \\
\hline Without insurance & 3749 & $97.4(97.0-98.1)$ & $25.6(23.4-27.9)$ \\
\hline \multicolumn{4}{|l|}{ Ethnicity } \\
\hline Mandinka & 1074 & $30.0(27.0-33.2)$ & $27.8(23.9-32.1)$ \\
\hline Wollof & 694 & $12.6(10.7-14.8)$ & $26.5(21.7-32.0)$ \\
\hline Fula & 939 & $20.9(18.3-23.8)$ & $21.1(16.7-26.2)$ \\
\hline Jola & 157 & $11.1(9.0-13.5)$ & $37.2(29.9-45.2)$ \\
\hline Sarahule & 402 & $9.1(6.6-12.5)$ & $11.6(8.7-15.5)$ \\
\hline Other & 246 & $7.7(6.5-9.2)$ & $33.4(26.2-41.4)$ \\
\hline Non Gambian & 278 & $8.6(7.6-9.6)$ & $19.3(13.4-27.0)$ \\
\hline \multicolumn{4}{|l|}{ Functional difficulties } \\
\hline Has functional difficulties & 86 & $2.2(1.9-2.6)$ & $42.3(29.1-56.6)$ \\
\hline Has no functional difficulties & 3648 & $97.8(97.4-98.1)$ & $25.0(22.8-27.4)$ \\
\hline \multicolumn{4}{|l|}{ Parity } \\
\hline $1-2$ & 1399 & $31.8(9.1-11.0)$ & $24.2(20.9-27.7)$ \\
\hline $3-4$ & 1141 & $26.3(25.2-27.5)$ & $22.3(18.9-26.2)$ \\
\hline $5+$ & 1250 & $32.0(30.4-33.4)$ & $29.5(26.3-33.0)$ \\
\hline \multicolumn{4}{|l|}{ Marital status } \\
\hline Currently married/in union & 3611 & $87.0(85.7-88.1)$ & $22.9(20.8-25.2)$ \\
\hline Formerly married/in union & 83 & $7.3(6.6-8.1)$ & $25.5(15.4-39.2)$ \\
\hline Single & 72 & $5.7(5.0-6.6)$ & $77.8(66.8-85.9)$ \\
\hline \multicolumn{4}{|l|}{ Age at first marriage } \\
\hline$<18$ & 1744 & $40.7(38.9-42.5)$ & $22.3(19.5-25.4)$ \\
\hline $18-24$ & 1632 & $42.9(41.3-44.5)$ & $24.0(21.3-26.9)$ \\
\hline $25+$ & 318 & $10.7(9.8-11.6)$ & $21.1(16.0-27.3)$ \\
\hline Never married & 96 & $5.7(5.0-6.6)$ & $78.1(67.1-86.1)$ \\
\hline \multicolumn{4}{|l|}{ LGA } \\
\hline Banjul & 186 & $1.3(1.1-1.4)$ & $30.5(22.6-39.6)$ \\
\hline Kanifing & 350 & $20.9(19.3-22.7)$ & $18.8(15.0-23.4)$ \\
\hline
\end{tabular}


Table 2 (continued)

\begin{tabular}{|c|c|c|c|}
\hline Variable & $\begin{array}{l}\text { Unweighted number of } \\
\text { women }\end{array}$ & $\begin{array}{l}\text { Weighted percentage of } \\
\text { women; } 95 \% \mathrm{Cl}\end{array}$ & $\begin{array}{l}\text { Weighted percentage of } \\
\text { unplanned pregnancy; } \\
95 \% \mathrm{Cl}\end{array}$ \\
\hline Brikama & 485 & $38.8(36.6-41.2)$ & $32.4(27.8-37.3)$ \\
\hline Mansakonko & 414 & $4.0(3.5-4.5)$ & $28.7(24.6-33.1)$ \\
\hline Kerewan & 514 & $10.3(9.2-11.5)$ & $33.3(29.2-37.6)$ \\
\hline Kuntaur & 617 & $4.8(4.3-5.3)$ & $19.0(14.7-24.2)$ \\
\hline Janjanbureh & 517 & $6.7(5.6-7.9)$ & $14.6(10.7-19.6)$ \\
\hline Basse & 707 & $13.3(11.3-15.6)$ & $13.8(11.0-17.2)$ \\
\hline \multicolumn{4}{|l|}{ Residential status } \\
\hline Urban & 1410 & $68.1(66.1-70.1)$ & $26.5(23.4-29.9)$ \\
\hline Rural & 2380 & $31.9(29.9-33.9)$ & $23.2(20.8-25.7)$ \\
\hline \multicolumn{4}{|l|}{ Overall happiness } \\
\hline Very happy & 1551 & $37.2(35.4-39.1)$ & $22.2(19.3-25.5)$ \\
\hline Somewhat happy & 1332 & $35.7(34.2-37.1)$ & $27.3(24.0-30.9)$ \\
\hline Neither happy nor unhappy & 721 & $21.6(20.5-22.7)$ & $25.7(21.7-30.2)$ \\
\hline Somewhat unhappy & 132 & $4.2(3.7-4.9)$ & $32.2(22.6-43.7)$ \\
\hline Very unhappy & 51 & $1.3(1.1-1.7)$ & $37.9(22.5-56.1)$ \\
\hline \multicolumn{4}{|l|}{ Sexual debut } \\
\hline$<18$ & 1064 & $24.6(23.2-26.0)$ & $27.0(22.8-31.6)$ \\
\hline $18+$ & 901 & $27.4(25.8-29.1)$ & $27.3(23.9-30.9)$ \\
\hline At first marriage & 1825 & $48.0(45.9-50.1)$ & $23.4(20.4-26.7)$ \\
\hline \multicolumn{4}{|l|}{ Ever used any method to avoid pregnancy } \\
\hline Yes & 468 & $20.7(19.3-22.1)$ & $28.1(22.8-34.1)$ \\
\hline No & 2633 & $79.3(77.9-80.7)$ & $23.5(20.8-26.4)$ \\
\hline \multicolumn{4}{|l|}{ Reading newspaper or magazine } \\
\hline No & 3584 & $89.1(87.9-90.3)$ & $25.3(23.0-27.7)$ \\
\hline Yes & 206 & $10.9(9.7-12.1)$ & $24.6(18.1-32.6)$ \\
\hline \multicolumn{4}{|l|}{ Listening to radio } \\
\hline No & 783 & $18.4(17.0-19.9)$ & $21.3(17.3-25.9)$ \\
\hline Yes & 3007 & $81.6(80.0-83.0)$ & $26.2(23.8-28.8)$ \\
\hline \multicolumn{4}{|l|}{ Watching television } \\
\hline No & 1733 & $32.0(29.2-35.0)$ & $24.2(20.6-28.3)$ \\
\hline Yes & 2055 & $68.0(65.0-70.8)$ & $25.9(23.4-28.6)$ \\
\hline \multicolumn{4}{|l|}{ Mobility } \\
\hline Native (lived $5+$ years in the location) & 2804 & $70.4(68.6-72.1)$ & $26.5(24.1-29.1)$ \\
\hline Visitor (lived < 5 years in the location) & 986 & $29.6(27.9-31.4)$ & $22.6(23.1-27.6)$ \\
\hline
\end{tabular}

pregnancy [19]. This is in line with results from a number of recent studies that looked at the prevalence of, and/or unmet needs for contraceptive use in The Gambia $[18,19]$. This is consistent with previous findings on the prevalence of unplanned or unintended pregnancy in several resource-poor settings. In SSA, there was a pooled 33.9\% prevalence of unintended pregnancy [4]. In Nigeria, Kenya and Ethiopia, this was about $11.0 \%$ and $24.0 \%$ respectively [29-31]. In a multi-country study, an overall unintended pregnancy prevalence rate of $29 \%$ was found, ranging from $10.8 \%$ in Nigeria to $54.5 \%$ in Namibia [16]. Results from the 2014 data showed a prevalence of $15.3 \%$ [16], whereas using the 2018 data, this increased to one-quarters indicating an upward trend.

While the Gambian government may have recognized the issue of unplanned pregnancies and committed to improving reproductive and sexual health care services, evidence suggests that there has been insufficient progress. Several factors were identified to be associated with unplanned pregnancy. In contrast to women aged 15-19 years, women in other age groups were more likely to have unplanned pregnancies, according to our research. This is consistent with the findings 
Table 3 Factors associated with unplanned pregnancy in The Gambia

\begin{tabular}{|c|c|c|c|c|}
\hline Variable & $\begin{array}{l}\text { Unadjusted odds ratio } \\
(95 \% \mathrm{Cl})\end{array}$ & $\mathbf{P}$ & Adjusted odds ratio $(95 \% \mathrm{Cl})$ & $P$ \\
\hline Age & & $<0.001^{*}$ & & \\
\hline $15-19$ & 1.00 & & 1.00 & \\
\hline $20-24$ & $1.00(0.81-1.23)$ & & $0.89(0.57-1.39)$ & 0.607 \\
\hline $25-29$ & $0.90(0.73-1.11)$ & & $0.62(0.38-1.01)$ & 0.056 \\
\hline $30-34$ & $1.07(0.86-1.32)$ & & $0.55(0.32-0.94)$ & $0.029^{*}$ \\
\hline $35-39$ & $1.41(1.13-1.76)$ & & $0.66(0.37-1.18)$ & 0.158 \\
\hline $40-44$ & $1.90(1.45-2.50)$ & & $0.68(0.35-1.34)$ & 0.265 \\
\hline $45-49$ & $1.81(1.15-2.85)$ & & $0.85(0.34-2.17)$ & 0.742 \\
\hline Household wealth quintiles & & 0.279 & & \\
\hline Poorest & 1.00 & & & \\
\hline Second & $1.16(1.02-1.1 .32)$ & & & \\
\hline Middle & $0.95(0.82-1.10)$ & & & \\
\hline Fourth & $1.16(0.99-1.36)$ & & & \\
\hline Richest & $0.93(0.77-1.11)$ & & & \\
\hline Education & & $0.086^{*}$ & & \\
\hline Pre-primary or none & 1.00 & & 1.00 & \\
\hline Primary & $0.99(0.86-1.13)$ & & $0.95(0.73-1.23)$ & 0.700 \\
\hline Secondary + & $1.21(1.08-1.36)$ & & $1.11(0.85-1.44)$ & 0.434 \\
\hline Health insurance & & $0.065^{*}$ & & \\
\hline With insurance & 1.00 & & 1.00 & \\
\hline Without insurance & $2.40(1.22-4.75)$ & & $7.28(0.95-55.62)$ & 0.056 \\
\hline Ethnicity & & $<0.001^{*}$ & & \\
\hline Mandinka & 1.00 & & 1.00 & \\
\hline Wollof & $1.05(0.91-1.21)$ & & $1.02(0.75-1.37)$ & 0.921 \\
\hline Fula & $0.64(0.55-0.74)$ & & $0.70(0.54-0.92)$ & $0.010^{*}$ \\
\hline Jola & $1.78(1.41-2.24)$ & & $1.02(0.64-1.62)$ & 0.939 \\
\hline Sarahule & $0.50(0.41-0.62)$ & & $0.77(0.52-1.13)$ & 0.187 \\
\hline Other & $1.38(1.14-1.69)$ & & $1.14(0.77-1.69)$ & 0.501 \\
\hline Non Gambian & $0.70(0.56-0.87)$ & & $0.55(0.36-0.86)$ & $0.008^{*}$ \\
\hline Functional difficulties & & $0.004^{*}$ & & \\
\hline Has functional difficulties & 1.00 & & 1.00 & \\
\hline Has no functional difficulties & $0.50(0.32-0.79)$ & & $0.53(0.30-0.91)$ & $0.021^{*}$ \\
\hline Parity & & $<0.001^{*}$ & & \\
\hline $1-2$ & 1.00 & & 1.00 & \\
\hline $3-4$ & $1.02(0.90-1.16)$ & & $1.79(1.34-2.39)$ & $<0.001^{*}$ \\
\hline $5+$ & $1.67(1.49-1.88)$ & & $3.02(2.08-4.39)$ & $<0.001^{*}$ \\
\hline Marital status & & $<0.001^{*}$ & & \\
\hline Currently married/in union & 1.00 & & 1.00 & \\
\hline Formerly married/in union & $1.28(0.92-1.77)$ & & $1.33(0.74-2.40)$ & 0.339 \\
\hline Single & $11.80(8.64-16.11)$ & & $11.38(6.38-20.29)$ & $<0.001^{*}$ \\
\hline Age at first marriage & & $<0.001^{*}$ & & \\
\hline$<18$ & 1.00 & & 1.00 & \\
\hline $18-24$ & $1.01(0.91-1.13)$ & & $0.96(0.77-1.19)$ & 0.696 \\
\hline $25+$ & $1.11(0.92-1.34)$ & & $1.23(0.84-1.80)$ & 0.278 \\
\hline Never married & $12.07(8.81-16.56)$ & & - & \\
\hline LGA & & $<0.001^{*}$ & & \\
\hline Banjul & 1.00 & & 1.00 & \\
\hline Kanifing & $0.53(0.40-0.69)$ & & $0.46(0.27-0.78)$ & $0.004^{*}$ \\
\hline Brikama & $1.02(0.81-1.30)$ & & $0.87(0.53-1.42)$ & 0.586 \\
\hline
\end{tabular}


Table 3 (continued)

\begin{tabular}{|c|c|c|c|c|}
\hline Variable & $\begin{array}{l}\text { Unadjusted odds ratio } \\
(95 \% \mathrm{Cl})\end{array}$ & $P$ & Adjusted odds ratio $(95 \% \mathrm{Cl})$ & $P$ \\
\hline Mansakonko & $0.90(0.70-1.15)$ & & $0.66(0.37-1.17)$ & 0.159 \\
\hline Kerewan & $1.12(0.88-1.42)$ & & $0.74(0.43-1.29)$ & 0.292 \\
\hline Kuntaur & $0.50(0.39-0.63)$ & & $0.33(0.18-0.59)$ & $<0.001^{*}$ \\
\hline Janjanbureh & $0.40(0.32-0.52)$ & & $0.27(0.15-0.48)$ & $<0.001^{*}$ \\
\hline Basse & $0.37(0.29-0.48)$ & & $0.35(0.20-0.62)$ & $<0.001^{*}$ \\
\hline Residential status & & $0.101^{*}$ & & \\
\hline Urban & 1.00 & & 1.00 & \\
\hline Rural & $0.88(0.79-0.97)$ & & $1.35(0.98-1.87)$ & 0.063 \\
\hline Overall happiness & & $0.172^{*}$ & & \\
\hline Very happy & 1.00 & & 1.00 & \\
\hline Somewhat happy & $1.20(1.07-1.35)$ & & $1.21(0.97-1.51)$ & 0.097 \\
\hline Neither happy nor unhappy & $1.22(1.06-1.40)$ & & $1.39(1.07-1.80)$ & $0.013^{*}$ \\
\hline Somewhat unhappy & $1.25(0.95-1.64)$ & & $1.24(0.74-2.09)$ & 0.417 \\
\hline Very unhappy & $1.47(0.98-2.22)$ & & $1.01(0.45-2.29)$ & 0.978 \\
\hline Sexual debut & & $0.003^{*}$ & & \\
\hline$<18$ & 1.00 & & 1.00 & \\
\hline $18+$ & $1.29(1.13-1.48)$ & & $1.34(1.01-1.77)$ & $0.042^{*}$ \\
\hline At first marriage & $0.94(0.84-1.06)$ & & $1.10(0.87-1.39)$ & 0.430 \\
\hline Ever used any method to avoid pregnancy & & $0.026^{*}$ & & \\
\hline Yes & 1.00 & & 1.00 & \\
\hline No & $0.77(0.66-0.89)$ & & $0.91(0.71-1.17)$ & 0.453 \\
\hline Reading newspaper or magazine & & 0.420 & & \\
\hline No & 1.00 & & & \\
\hline Yes & $1.15(0.93-1.42)$ & & & \\
\hline Listening to radio & & $0.084^{*}$ & & \\
\hline No & 1.00 & & 1.00 & \\
\hline Yes & $1.18(1.04-1.34)$ & & $0.97(0.76-1.23)$ & 0.800 \\
\hline Watching television & & $0.003^{*}$ & & \\
\hline No & 1.00 & & 1.00 & \\
\hline Yes & $1.27(1.14-1.40)$ & & $1.20(0.97-1.48)$ & 0.093 \\
\hline Mobility & & $0.100^{*}$ & & \\
\hline Native (lived $5+$ years in the location) & 1.00 & & 1.00 & \\
\hline Visitor (lived < 5 years in the location) & $0.86(0.76-0.97)$ & & $1.13(0.89-1.44)$ & 0.329 \\
\hline
\end{tabular}

from a previous study [16]. Also, this result is in line with a study by Hubacher, Mavranezouli, and McGinn [32], who examined the prevalence of unintended pregnancies in SSA and the possible role of contraceptive implants in reducing them. They discovered that women aged $20-24,25-29$, and 30-34 years had the highest proportion of unintended pregnancies, compared to those aged 15-19 years [32]. According to Calvert et al. [33], who also reported from Tanzania, the risk of unplanned pregnancies rises with age. This result may be clarified by the fact that adult women might already have the ideal number of children and thus view any additional pregnancy as undesired or unplanned. Furthermore, women who had no functional difficulties had reduction in unplanned pregnancy, when compared with those with functional difficulties. Women with functional difficulties may lack physical accessibility to sexual and reproductive health care services, such as contraceptive products and health information as access to health information has been reported to have positive impact to health-seeking behaviour [34-37].

Furthermore, unplanned pregnancies were more common among single or unmarried women. This is consistent with the findings from a previous study which indicated that increased risk of unplanned pregnancy among single women [31], could be attributed to non-use of contraception or contraceptive failure, as certain single women may assume that contraceptive use has significant 
Table 4 Predictive margins of unplanned pregnancy among women of reproductive age in The Gambia

\begin{tabular}{ll}
\hline Variable & $\begin{array}{l}\text { Predictive } \\
\text { margins }\end{array}$ \\
\hline
\end{tabular}

\section{Age}

15-19

20-24

25-29

30-34

35-39

40-44

45-49

Education

Pre-primary or none
Primary
Secondary+

Health insurance

With insurance

Without insurance

Ethnicity

Mandinka

Wollof

Fula

Jola

Sarahule

Other

Non Gambian

Functional difficulties

\section{Has functional difficulties}

Has no functional difficulties

Parity

1-2

3-4

$5+$

LGA

\begin{tabular}{lll} 
Banjul & 33.3 & $23.7-43.0$ \\
Kanifing & 19.5 & $13.5-25.4$ \\
Brikama & 30.6 & $24.4-36.8$ \\
Mansakonko & 25.5 & $20.8-30.2$ \\
Kerewan & 27.6 & $23.0-32.2$ \\
Kuntaur & 15.1 & $11.8-18.5$ \\
Janjanbureh & 12.7 & $9.4-16.0$ \\
Basse & 16.0 & $12.6-19.3$ \\
Residential status & & \\
$\quad$ Urban & 18.2 & $15.3-21.1$ \\
Rural & 22.6 & $20.2-25.0$ \\
Overall happiness & & \\
$\quad$ Very happy & 18.8 & $16.7-20.9$ \\
Somewhat happy & 21.6 & $19.2-23.9$ \\
Neither happy nor unhappy & 23.8 & $20.5-27.1$ \\
$\quad$ Somewhat unhappy & 22.0 & $14.3-29.7$ \\
Very unhappy & 19.0 & $7.9-30.1$ \\
\hline
\end{tabular}

20.2-25.6

$19.3-27.1$

15.0-20.5

$16.1-30.3$

14.1-23.9

19.2-31.0

10.3-19.3

21.2-42.0

19.2-22.0

11.6-16.1

18.5-23.9

26.0-34.2
Table 4 (continued)

\begin{tabular}{lll}
\hline Variable & $\begin{array}{l}\text { Predictive } \\
\text { margins }\end{array}$ & $\mathbf{9 5 \%} \mathbf{C l}$ \\
\hline $\begin{array}{l}\text { Sexual debut } \\
\quad<18\end{array}$ & 19.2 & $16.5-21.8$ \\
$\quad 18+$ & 23.5 & $20.3-26.7$ \\
$\quad$ At first marriage & 20.5 & $18.5-22.5$ \\
Ever used any method to avoid pregnancy & & \\
$\quad$ Yes & 22.1 & $18.5-25.6$ \\
$\quad$ No & 20.6 & $19.1-22.1$ \\
Listening to radio & & \\
$\quad$ No & 21.2 & $18.0-24.4$ \\
$\quad$ Yes & 20.7 & $19.2-22.3$ \\
Watching television & & \\
$\quad$ No & 19.4 & $17.3-21.5$ \\
$\quad$ Yes & 22.1 & $20.0-24.2$ \\
Mobility & & \\
$\quad$ Native (lived 5 + years in the location) & 20.4 & $18.8-22.0$ \\
$\quad$ Visitor (lived <5 years in the location) & 22.2 & $19.1-25.4$ \\
\hline
\end{tabular}

side effects [38], whereas others may believe that it reduces sexual pleasure, and therefore have unprotected intercourse, raising the risk of unplanned pregnancies [22, 38-42]. In addition, higher parity was a predisposing factor of unplanned pregnancy [31]. Women with higher number of children ever born could be regarded as already having the desired number of children and thus consider any additional pregnancy as unplanned or unwanted. On the other hand, women aged $18+$ at sexual debut had higher odds of unplanned pregnancy. This is contrary to a previous study which found that unplanned pregnancy was associated with younger age at sexual debut [33].

Unplanned pregnancies were found to be substantially correlated with geographic area and ethnicity [29]. We found the Fulas and non-Gambian women had reduction in unplanned pregnancy respectively, when compared with the Mandinka women. In addition, women's LGA of origin was significantly associated with unplanned pregnancy. It is possible there are more healthcare institutions in certain geographical locations, or related interventions may have been conducted within an ethnic group or geographical locations. The geospatial differentials in health care service utilization has been reported in previous studies [43-46].

\section{Strengths and limitations}

The strengths of this analysis are that the pregnancy aim determination was not affected by the result of pregnancy and that the probability of recall bias was minimized because the data were only obtained for the index 
pregnancy. The use of population-based data was useful and representative for plausible comparisons. There are still, however, some drawbacks. First, other scholars raised doubts about how planned and unplanned pregnancies are described (for example, since the reactions of a woman to a pregnancy she has categorized as unplanned may be conflicting or ambivalent), as well as about discrepancies between the purpose of a woman and her pregnancy feelings. Therefore, it may be a limitation of our research to use a single item to assess pregnancy intent. Second, we were unable to find causal links between the purpose of pregnancy and the established risk factors because of the cross-sectional study design.

\section{Conclusion}

This research showed that the prevalence of unplanned pregnancy was relatively high $(25.3 \%)$ in the study settings, indicating the need for more exposure to this issue. Family planning services for women of reproductive age, especially those at high risk of unplanned pregnancy, should be accessible widely and easily. Our findings indicate, in particular, that better sex education and increased awareness of contraceptive methods are required for women. In addition, to improve the efficacy and quality of the use of contraceptive methods, women without family support can require individualized guidance and counselling.

\section{Abbreviations}

Cl: Confidence Interval; GBS: Gambia Bureau of Statistics; LGA: Local Government Area; MRC: Medical Research Council; MICS: Multiple Indicator Cluster Survey; NDP: National Development Plan; NRHP: National Reproductive Health Policy; SCC: Scientific Coordinating Committee; SSA: Sub-Saharan Africa; SDG: Sustainable Development Goal; TX: Texas; UNICEF: United Nations International Children's Emergency Fund; USA: United States of America.

\section{Acknowledgements}

The author's appreciation goes to the MICS project for the approval and access granted to the original data for this research.

\section{Authors' contributions}

$A B, A J, S B, E T, M E$ conceived and designed the study, reviewed the literature. $M E, A B$ performed data analysis and wrote the results. $A B, A J, S B, E T, M E$ discussed the findings and provided substantial inputs in the draft of the paper. $A B$ had the final responsibility to submit the manuscript. All authors read and approved the final version of the paper.

\section{Funding}

There is no funding or grant by any organization or funding agency both in not-for-profit, profit or the public for this study.

\section{Availability of data and materials}

The issue of privacy of the respondents was considered such that exclusive information such as respondents' locations and their names as collected during the MICS interviews were consciously removed from datasets. These data files are made available on; www.gbosdata.org and on the MICS website and can be freely downloaded for legitimate research purposes.

\section{Declarations}

Ethics approval and consent to participate

Ethics approval for this study was not required since the data is secondary and is available in the public domain. All methods were carried out in accordance with relevant guidelines and regulations. More details regarding MICS data and ethical standards are available at: www.gbosdata.org

\section{Consent for publication}

MICS is a de-identified open-source dataset. Therefore, the requirement of consent for publication is not applicable.

\section{Competing interests}

This research was done without any financial or commercial dealings that may be interpreted as a possible conflict of interest and the authors declared so.

\section{Author details}

${ }^{1}$ Department of Public \& Environmental Health, School of Medicine \& Allied Health Sciences, University of The Gambia, Kanifing, The Gambia. ${ }^{2}$ Department of Obstetrics and Gynaecology, Edward Francis Small Teaching Hospital, Banjul, The Gambia. ${ }^{3}$ Public Health Unit, Brikama District Hospital, Ministry of Health, West Coast Region, Brikama, The Gambia. ${ }^{4}$ School of Public Health, Gambia College, West Coast Region, Brikama, The Gambia. ${ }^{5}$ Department of Epidemiology and Medical Statistics, Faculty of Public Health, College of Medicine, University of Ibadan, Ibadan, Nigeria.

Received: 16 April 2021 Accepted: 28 December 2021

Published online: 06 January 2022

\section{References}

1. Ganatra B, Gerdts C, Rossier C, Johnson BR, Tunçalp Ö, Assifi A, et al. Global, regional, and subregional classification of abortions by safety, 2010-14: estimates from a Bayesian hierarchical model. The Lancet. 2017;390:2372-81. https://doi.org/10.1016/S0140-6736(17)31794-4.

2. Bearak J, Popinchalk A, Ganatra B, Moller A-B, Tunçalp Ö, Beavin C, et al. Unintended pregnancy and abortion by income, region, and the legal status of abortion: estimates from a comprehensive model for 1990-2019. Lancet Glob Health. 2020;8:e1152-61. https://doi.org/10. 1016/S2214-109X(20)30315-6.

3. Bearak J, Popinchalk A, Alkema L, Sedgh G. Global, regional, and subregional trends in unintended pregnancy and its outcomes from 1990 to 2014: estimates from a Bayesian hierarchical model. Lancet Glob Health. 2018;6:e380-9. https://doi.org/10.1016/S2214-109X(18)30029-9.

4. Bain LE, Zweekhorst MBM, Buning T de C. Prevalence and Determinants of Unintended Pregnancy in Sub -Saharan Africa: A Systematic Review. Afr J Reprod Health. 2020;24. Available: https://www.ajrh.info/index.php/ ajrh/article/view/2234

5. Sedgh G, Bearak J, Singh S, Bankole A, Popinchalk A, Ganatra B, et al. Abortion incidence between 1990 and 2014: global, regional, and subregional levels and trends. The Lancet. 2016;388:258-67. https://doi.org/10. 1016/S0140-6736(16)30380-4.

6. Bongaarts J, Mensch BS, Blanc AK. Trends in the age at reproductive transitions in the developing world: The role of education. Popul Stud. 2017;71:139-54. https://doi.org/10.1080/00324728.2017.1291986.

7. Alkema L, Kantorova V, Menozzi C, Biddlecom A. National, regional, and global rates and trends in contraceptive prevalence and unmet need for family planning between 1990 and 2015: a systematic and comprehensive analysis. The Lancet. 2013;381:1642-52. https://doi.org/10.1016/ S0140-6736(12)62204-1.

8. Peterson HB, Darmstadt GL, Bongaarts J. Meeting the unmet need for family planning: now is the time. The Lancet. 2013;381:1696-9. https:// doi.org/10.1016/S0140-6736(13)60999-X.

9. Ahmed S, Li Q, Liu L, Tsui AO. Maternal deaths averted by contraceptive use: an analysis of 172 countries. The Lancet. 2012;380:111-25. https:// doi.org/10.1016/S0140-6736(12)60478-4.

10. Endriyas M, Eshete A, Mekonnen E, Misganaw T, Shiferaw M, Ayele S Contraceptive utilization and associated factors among women of 
reproductive age group in Southern Nations Nationalities and Peoples' Region, Ethiopia: cross-sectional survey, mixed-methods. Contracept Reprod Med. 2017;2. doi:https://doi.org/10.1186/s40834-016-0036-z

11. New JR, Cahill N, Stover J, Gupta YP, Alkema L. Levels and trends in contraceptive prevalence, unmet need, and demand for family planning for 29 states and union territories in India: a modelling study using the Family Planning Estimation Tool. Lancet Glob Health. 2017;5:e350-8. https://doi. org/10.1016/S2214-109X(17)30033-5.

12. Carr B, Gates MF, Mitchell A, Shah R. Giving women the power to plan their families. The Lancet. 2012;380:80-2. https://doi.org/10.1016/S01406736(12)60905-2.

13. Singh S, Darroch JE. Adding It Up: Costs and Benefits of Contraceptive Services-Estimates for 2012, New York: Guttmacher Institute and United Nations Population Fund (UNFPA), http://www.guttmacher.org/pubs/ AlU-2012-estimates.pdf. 2012; 28

14. Rosa W, editor. Transforming Our World: The 2030 Agenda for Sustainable Development. A New Era in Global Health. New York, NY: Springer Publishing Company; 2017. doi:https://doi.org/10.1891/9780826190123.ap02

15. Idoko P, Nkeng G, Anyawu M. Reasons for current pregnancy amongst grand multiparous Gambian women - a cross sectional survey. BMC Pregnancy Childbirth. 2016;16:217. https://doi.org/10.1186/s12884-016-1016-7.

16. Ameyaw EK, Budu E, Sambah F, Baatiema L, Appiah F, Seidu A-A, et al. Prevalence and determinants of unintended pregnancy in sub-Saharan Africa: A multi-country analysis of demographic and health surveys. R Kabir, editor. PLoS One. 2019;14:e0220970. https://doi.org/10.1371/journal.pone.0220970.

17. The Gambia Bureau of Statistics (GBOS) and ICF International. 2014. The Gambia Demographic and Health Survey 2013. Banjul, The Gambia, and Rockville, Maryland, USA: GBOS and ICF International. Available: https:// dhsprogram.com/pubs/pdf/FR289/FR289.pdf

18. Barrow A. A Survey on Prevalence and Knowledge of Family Planning among Women of Childbearing Age in the Provincial Settings of the Gambia: A Descriptive Cross-Sectional Study. Silva DAS, editor. Adv Prev Med. 2020;2020:1-12. https://doi.org/10.1155/2020/8862290.

19. Barrow A, Jobe A, Okonofua F. Prevalence and determinants of unmet family planning needs among women of childbearing age in The Gambia: analysis of nationally representative data. Gates Open Res. 2021;4:124. https://doi.org/10.12688/gatesopenres.13175.2.

20. Eliason S, Awoonor-Williams JK, Eliason C, Novignon J, Nonvignon J, Aikins M. Determinants of modern family planning use among women of reproductive age in the Nkwanta district of Ghana: a case-control study. Reprod Health. 2014;11:65. https://doi.org/10.1186/1742-4755-11-65.

21. Blackstone SR, Nwaozuru U, Iwelunmor J. Factors Influencing Contraceptive Use in Sub-Saharan Africa: A Systematic Review. Int Q Community Health Educ. 2017;37:79-91. https://doi.org/10.1177/0272684X16685254.

22. Osinowo K, Ekholuenetale M, Ojomo O, Hassan A, Ladipo OA. Patterns of triggers, ideation and motivational factors of contraceptive utilization among women and gate-keepers in Nigeria: a scoping study on the resilient and accelerated scale up of DMPA-SC in Nigeria (RASUDIN). Contracept Reprod Med. 2020;5:38. https://doi.org/10.1186/s40834-020-00141-6.

23. Apanga PA, Adam MA. Factors influencing the uptake of family planning services in the Talensi District, Ghana. Pan Afr Med J. 2015;20. doi:https:// doi.org/10.11604/pamj.2015.20.10.5301

24. Hruschka DJ, Gerkey D, Hadley C. Estimating the absolute wealth of households. Bull World Health Organ. 2015;93:483-90. https://doi.org/10. 2471/BLT.14.147082.

25. Rutstein SO, Staveteig S. Making the Demographic and Health Surveys Wealth Index Comparable. 2014; DHS Methodological Reports No. 9. Rockville, Maryland, USA: ICF International.

26. Midi H, Sarkar SK, Rana S. Collinearity diagnostics of binary logistic regression model. J Interdiscip Math. 2010;13:253-67. https://doi.org/10.1080/ 09720502.2010.10700699.

27. Williams R. Using the Margins Command to Estimate and Interpret Adjusted Predictions and Marginal Effects. Stata J Promot Commun Stat Stata. 2012:12:308-31. https://doi.org/10.1177/1536867X1201200209.

28. Ekholuenetale M, Adeyoju TO, Onuoha H, Barrow A. Renal Failure among Women of Reproductive Age in Burundi: Estimating the Prevalence and Associated Factors Using Population-Based Data. Kershaw DB, editor. Int $J$ Nephrol. 2021;2021:1-11. https://doi.org/10.1155/2021/6640495.

29. Yaya S, Amouzou A, Uthman OA, Ekholuenetale M, Bishwajit G, Udenigwe $O$, et al. Prevalence and determinants of terminated and unintended pregnancies among married women: analysis of pooled cross-sectional surveys in Nigeria. BMJ Glob Health. 2018;3: e000707. https://doi.org/10. 1136/bmjgh-2018-000707.

30. Habte D, Teklu S, Melese T, Magafu MGMD. Correlates of Unintended Pregnancy in Ethiopia: Results From a National Survey. PLoS One. 2013;8:e82987. https://doi.org/10.1371/journal.pone.0082987.

31. Ikamari L, Izugbara C, Ochako R. Prevalence and determinants of unintended pregnancy among women in Nairobi. Kenya BMC Pregnancy Childbirth. 2013;13:69. https://doi.org/10.1186/1471-2393-13-69.

32. Hubacher D, Mavranezouli I, McGinn E. Unintended pregnancy in subSaharan Africa: magnitude of the problem and potential role of contraceptive implants to alleviate it. Contraception. 2008;78:73-8. https://doi. org/10.1016/j.contraception.2008.03.002.

33. Calvert C, Baisley K, Doyle AM, Maganja K, Changalucha J, Watson-Jones $D$, et al. Risk factors for unplanned pregnancy among young women in Tanzania. J Fam Plann Reprod Health Care. 2013;39:e2-e2. https://doi.org/ 10.1136/jprhc-2012-100389.

34. Dutta MJ. Health information processing from television: the role of health orientation. Health Commun. 2007;21:1-9. https://doi.org/10. 1080/10410230701283256.

35. Babalola S, Figueroa M-E, Krenn S. Association of Mass Media Communication with Contraceptive Use in Sub-Saharan Africa: A Meta-Analysis of Demographic and Health Surveys. J Health Commun. 2017 [cited 21 Mar 2019]. Available: https://www.tandfonline.com/doi/abs/https://doi.org/ 10.1080/10810730.2017.1373874

36. Ajaero CK, Odimegwu C, Ajaero ID, Nwachukwu CA. Access to mass media messages, and use of family planning in Nigeria: a spatio-demographic analysis from the 2013 DHS. BMC Public Health. 2016;16:427. https://doi.org/10.1186/s12889-016-2979-z.

37. Zamawe COF, Banda M, Dube AN. The impact of a community driven mass media campaign on the utilisation of maternal health care services in rural Malawi. BMC Pregnancy Childbirth. 2016;16:21. https://doi.org/10. 1186/s12884-016-0816-0

38. Hindin MJ, McGough LJ, Adanu RM. Misperceptions, misinformation and myths about modern contraceptive use in Ghana. J Fam Plann Reprod Health Care. 2014:40:30-5. https://doi.org/10.1136/ffprhc-2012-100464.

39. Liu J, Shen J, Diamond-Smith N. Predictors of DMPA-SC continuation among urban Nigerian women: the influence of counseling quality and side effects. Contraception. 2018;98:430-7. https://doi.org/10.1016/j.contr aception.2018.04.015.

40. Ankomah A, Anyanti J, Adebayo SB, Giwa A. Barriers to Contraceptive Use among Married Young Adults in Nigeria: A Qualitative Study. 2014. https://doi.org/10.9734/ijtdh/2013/4573.

41. Muanda MF, Ndongo GP, Messina LJ, Bertrand JT. Barriers to modern contraceptive use in rural areas in DRC. Cult Health Sex. 2017;19:1011-23. https://doi.org/10.1080/13691058.2017.1286690.

42. Ochako R, Mbondo M, Aloo S, Kaimenyi S, Thompson R, Temmerman $\mathrm{M}$, et al. Barriers to modern contraceptive methods uptake among young women in Kenya: a qualitative study. BMC Public Health. 2015;15. doi:https://doi.org/10.1186/s12889-015-1483-1

43. Tanou M, Kamiya Y. Assessing the impact of geographical access to health facilities on maternal healthcare utilization: evidence from the Burkina Faso demographic and health survey 2010. BMC Public Health. 2019;19:838. https://doi.org/10.1186/s12889-019-7150-1.

44. Uthman OA. Geographical variations and contextual effects on age of initiation of sexual intercourse among women in Nigeria: a multilevel and spatial analysis. Int J Health Geogr. 2008;7:27. https://doi.org/10.1186/ 1476-072X-7-27.

45. Krenn S, Cobb L, Babalola S, Odeku M, Kusemiju B. Using behavior change communication to lead a comprehensive family planning program: the Nigerian Urban Reproductive Health Initiative. Glob Health Sci Pract. 2014;2:427-43. https://doi.org/10.9745/GHSP-D-14-00009.

46. Ekholuenetale M, Benebo FO, Idebolo AF. Individual-, household-, and community-level factors associated with eight or more antenatal care contacts in Nigeria: Evidence from Demographic and Health Survey. PLoS ONE. 2020;15: e0239855. https://doi.org/10.1371/journal.pone.0239855.

\section{Publisher's Note}

Springer Nature remains neutral with regard to jurisdictional claims in published maps and institutional affiliations. 